\title{
On the Design of Partial Discharge-Free Low Voltage Electrical Machines
}

\author{
Vincenzo Madonna ${ }^{1}$, Paolo Giangrande ${ }^{1}$, Weiduo Zhao $^{2}$, He Zhang ${ }^{2}$, Chris Gerada ${ }^{1,2}$, Michael Galea ${ }^{1,2}$ \\ ${ }^{1}$ PEMC Group, University of Nottingham, Nottingham, NG72RD, UK, p.giangrande@nottingham.ac.uk \\ ${ }^{2}$ PEMC Group, University of Nottingham Ningbo China, Ningbo, 315100, China
}

\begin{abstract}
Modern electrical machines employed in transportation applications are required to provide high performance in terms of power (and torque) density. At the same time, being these applications safety-critical, a significant level of reliability and/or fault tolerance is expected. Among all the factors which can compromise motors reliability, partial discharges inception is one of the most critical, in particular for low voltage, random wound machines. In this paper, the influence of insulation design choices on the performance of a traction electric motor are analysed. The study is based on the Paschen's law for air at sea-level pressure combined with an electrostatic finite element model of the turn-to-turn insulation subsystems, built for determining the electric field. The finite element analysis findings are experimentally validated by detecting the partial discharges inception, on custom-built prototypes.
\end{abstract}

Index Terms - Electrical Machines Design, Partial Discharges, Reliability, Organic Insulation, Automotive

\section{INTRODUCTION}

Insulation related problems represent one the main causes of premature failures in electrical machines (EMs). The adoption of modern variable speed drives (VSDs) has been widely recognised, by the scientific community, as one of the primary reasons of EMs insulation over-stress [1, 2]. The combination of fast switching devices (i.e. high $\mathrm{dV} / \mathrm{dt}$ ) and long cables between power electronics converter (PEC) and EM can cause non-negligible voltage magnitude amplification at the motor side [3, 4].

Depending on the voltage level, the insulation system of EMs is classified by technical standards in Type-I and Type-II $[5,6]$. Electrical machines with rated voltage above $700 \mathrm{Vrms}$, tend to be equipped with form-wound coils, whose insulation is a mix of organic and inorganic materials (i.e. Type-II insulation) [6]. Type-II insulation systems are also identified as partial discharges (PD) -resistant as they can withstand PD, which are electrical discharges that only partially bridges the insulation between two electrical conductors. Thus, EMs manufactured adopting Type II insulation are expected to

This work was funded by the INNOVATIVE doctoral programme. The INNOVATIVE programme is partially funded by the Marie Curie Initial Training Networks (ITN) action (project number 665468) and partially by the Institute for Aerospace Technology (IAT) at the University of Nottingham.

This work was also supported in part by the National Key Research Program of China under Grant 2017YFB0102304, and in part by the Ningbo Natural Science Foundation under Grant 2018A610148.

This work was also supported by the Ningbo 3315 Innovation Team Scheme under Grant 2018A-08-C. experience PD as a result of voltage impulses from the inverter [7]. Despite PD are low energy phenomenon, their inception causes the progressive insulation degradation, even in Type-II insulation, generally modelled through an inverse power law. On the contrary, low voltage EMs (i.e. rated voltage $<700$ Vrms) are commonly manufactured using Type-I insulation (i.e. organic chemical composition). Organic insulating materials do not have the ability to withstand PD, which might cause the EM out-of-service within few hours/days after their repetitive inception. Therefore, Type-I-insulated EMs should be designed to be PD-free throughout their whole lifetime. Despite this criticality, organic-insulated EMs are largely adopted in a wide range of applications, some of which are safety-critical (e.g. aerospace and automotive) [8-12]. For transportation applications, EMs are generally designed with some degree of fault-tolerance, which allows to safely complete a mission even during/after severe faults [13]. This is conventionally achieved adopting particular choices at design stage (e.g. multiphase windings) and applying some corrective control strategies depending on the fault nature [14, 15]. On the other hand, a reliable EM is not expected to experience failures throughout its useful lifetime. Thus, in order to implement a reliability-oriented design, it is necessary a precise knowledge of the EM mission profile, operating environment, drive characteristics and any other source of stress which might arise during real operations [16, 17]. Nonetheless, the adoption of "over-protective measures" (e.g. use of thicker insulating materials), while positively influencing reliability, it might negatively affect the EM performance (e.g. torque and power densities) [18].

This paper investigates how the choice of a PD-free design can affect the performance of a low voltage permanent magnet synchronous machine (PMSM). In particular, the impact of both insulation thickness (i.e. grade) and magnet wire diameter on the electromagnetic torque is analysed. A $\mathrm{V}$-Shaped interior permanent magnet EM, designed for traction application, is selected as a study-case. Nevertheless, the research outcomes have general validity and can be extended to different EMs topologies.

\section{Voltage Enhancement at Machine Terminals}

In VSDs, the voltage amplitude at the EM terminals can be higher than the one at the inverter side due to waveform reflection $[3,19,20]$. This voltage enhancement is contingent on the combination between short rise-time waveforms and long length cables. Transient over-voltages occurring in VSDs can be studied relying on basic transmission line theory and equivalent circuit simulations [21]. For an accurate 
description of this phenomena, it is required to have a precise knowledge of the motor and cable equivalent impedances as a response to high frequencies impulses. However, it has been widely demonstrated in literature $[4,21,22]$ and in technical standards [5] that simplified lumped parameter circuital models can precisely estimate the magnitude of the voltage amplification.

By defining the incident wave $e_{i}$, the resulting voltage at the end of the cable, $e_{m}$, can be calculated as in (1), where $Z_{M}$ is the EM (surge) impedance and $Z_{C}$ is the cable characteristic surge impedance [23, 24].

$$
e_{m}=\frac{2 \cdot Z_{M}}{Z_{M}+Z_{C}} \cdot e_{i}
$$

The maximum voltage amplification (i.e. worst-case) is achieved when $Z_{M}>>Z_{C}$ (i.e. approaching an open-circuit line). In this case the voltage is amplified by a factor of 2 .

The voltage wave travels along the cable with a speed equal to the speed of light $c$ (i.e. $\approx 3 \cdot 10^{8} \mathrm{~m} / \mathrm{s}$ ) multiplied by the velocity factor $V F(<1)$. The latter can be calculated as in (2), where $\mu_{r}$ and $\varepsilon_{r}$ are the cable relative permeability and dielectric constant respectively.

$$
V F=\frac{1}{\sqrt{\mu_{r^{\prime} \varepsilon_{r}}}}
$$

The dielectric constant of a three-conductor PVC cable can be assumed equal to 4.5 , whilst it is reasonable to assume $\mu_{\mathrm{r}}=1[3,21]$. Therefore, the voltage wave travels along the cable at a speed equal to $0.5 \mathrm{c}$ (i.e. $1.5 \cdot 10^{8} \mathrm{~m} / \mathrm{s}$ ).

The equivalent circuit of PEC, cable and EM has been implemented in the circuit simulation software LTspice ${ }^{\circledR}$ as shown in Fig. 1.a. An example of simulation outcome is reported in Fig. 1.b for a waveform rise time $t_{r}=50 \mathrm{~ns}$ and a cable length of $5 \mathrm{~m}$.

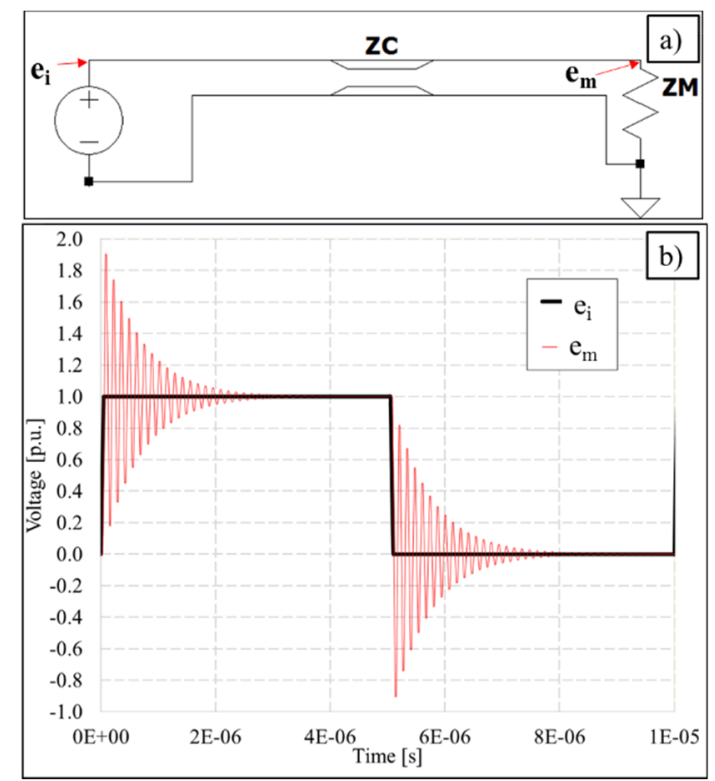

Fig. 1 (a) Simplified circuit representation of PEC, cable and EM implemented in LTspice ${ }^{\mathbb{B}}$ and (b) simulation outcome for $\mathrm{t}_{\mathrm{r}}=50 \mathrm{~ns}$ and $5 \mathrm{~m}$ cable length.

The technical standard IEC 60034-18-41 [5] lists the overvoltage factor $O F$ (i.e. ratio between peak voltage at EM and PEC terminals) as a function of the cable length for different rise times ranging from $50 \mathrm{~ns}$ to $1 \mu \mathrm{s}$. Nonetheless, recent $\mathrm{SiC}$ MOSFETs devices features times below $50 \mathrm{~ns}$ [25] and the newest ones claim rise time of $11 \mathrm{~ns}$ [26]. Therefore, relying on the equivalent circuit reported in Fig. 1.a, the $O F$ is determined for several cable lengths ranging from 0.1 up to $5.5 \mathrm{~m}$ and four rise time values, i.e. 10, 20, 30 and $50 \mathrm{~ns}$. The simulations outcomes are summarized in Fig. 2. As expected, for a given cable length, the faster is the rise time the higher is the $O F$.

The peak voltage at the EM terminals $V_{p}$ can be calculated as in (3), where $V_{D C}$ is the DC link voltage (voltage drops are neglected because of their modest influence) [27].

$$
V_{p}=V_{D C} \cdot O F
$$

The voltage stressing the turn-to-turn insulation is closely related to the rise time $t_{r}$ of the applied waveform through (4), where $K\left(t_{r}\right)$ is a coefficient whose value is $<1$ [5].

$$
V_{t-t}=K\left(t_{r}\right) \cdot 0.7 \cdot V_{D C} \cdot O F
$$

In the worst-case scenario, i.e. a short $t_{r}$ and the first turn of a coil adjacent to the last one, then $K\left(t_{r}\right)$ can be assumed $\approx 1$. It is worth remarking that (3) to (4) refer to a 2-level PEC whose control algorithm avoids waveform double transitions. In fact, if the PEC is not provided with this feature, even higher voltage amplifications can be expected during the transition from a positive to a negative PWM step voltage (and vice-versa).

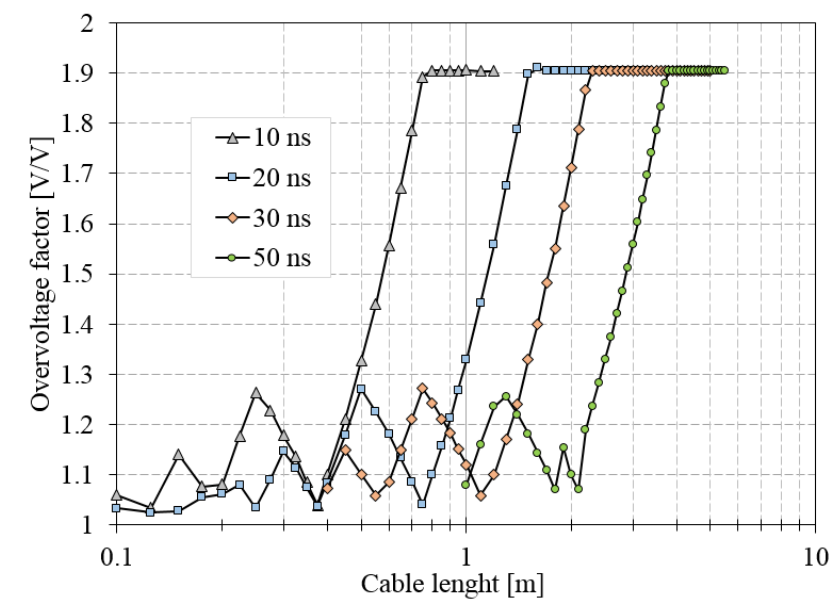

Fig. 2 Overvoltage factor vs. cable length for different rise times (i.e. 10, $20,30$ and $50 \mathrm{~ns})$.

To achieve for PD-free in low voltage EMs turn-to-turn insulation, the voltage level calculated in (4) must be multiplied by an enhancement factor $E F$, which accounts for insulation aging and/or harsh environmental conditions. The $E F$ advised in the technical standard [5] ranges from 1.25 to 1.63. It is necessary that the PD inception voltage (PDIV) for each insulation subsystem (i.e. phase-to-phase, phase-to-ground and turn-to-turn) is beyond the corresponding peak voltage times the $E F$. In this work only the analysis relative to the turn-to-turn insulation subsystem (i.e. weakest insulation part) will be presented. Hence, an inequality can be introduced as expressed by (5) for guaranteeing a PD-free turn-to-turn insulation.

$$
P D I V_{t-t}>V_{t-t} \cdot E F
$$




\section{TURN TO TURN INSULATION ANALYSIS}

According to Paschen's law [28], the turn-to-turn insulation subsystem is examined. Since EMs for traction applications are not expected to operate at low ambient pressure (i.e. high altitude), the Paschen's curve at standard sea-level pressure is assumed, as shown in Fig. 3. To avoid the PD inception, the electric field $E_{b}$ in any air inclusion, within the EM's insulation, should be lower than the Paschen's limit (i.e. curve reported in Fig. 3).

In low voltage random wound EMs, the insulation between turns is a thin layer of enamel (e.g. polyamide, polyimide, polyester-imide etc.) and impregnating resin/varnish [29]. Air inclusions between adjacent turns might still exist after the impregnation process and this mainly depends on the impregnation technology/quality. Being the machine randomly wound, it might occur that the first turn of a coil is in direct contact with the last turn. Thus, the turn insulation must be able to withstand the total coil's voltage, without experiencing PD. In addition, the turn-to-turn voltage can be enhanced as explained in Section II.

Compatibly with the EM slot geometry, several wire diameters and insulation grades (i.e. thickness) have been simulated through an electrostatic finite element (FE) software, supervised by a custom-designed script. These simulations aimed to determine the electric field in the air space between two turns, while the obtained results have been analytically post-processed for calculating the PDIV. In Fig. 4, the model widely described in literature [30], and implemented for the turn-to-turn PDIV analysis is depicted, where $d$ defines the gap between conductors, $V_{\text {peak }}$ is the applied peak voltage, whilst $D_{\text {in }}$ and $D_{\text {out }}$ are the bare conductor (i.e. copper only) and the overall wire (i.e. copper+enamel) diameters respectively. By filling the wedgeshaped space between two conductors with air (i.e. no impregnation), a conservative investigation is carried out.

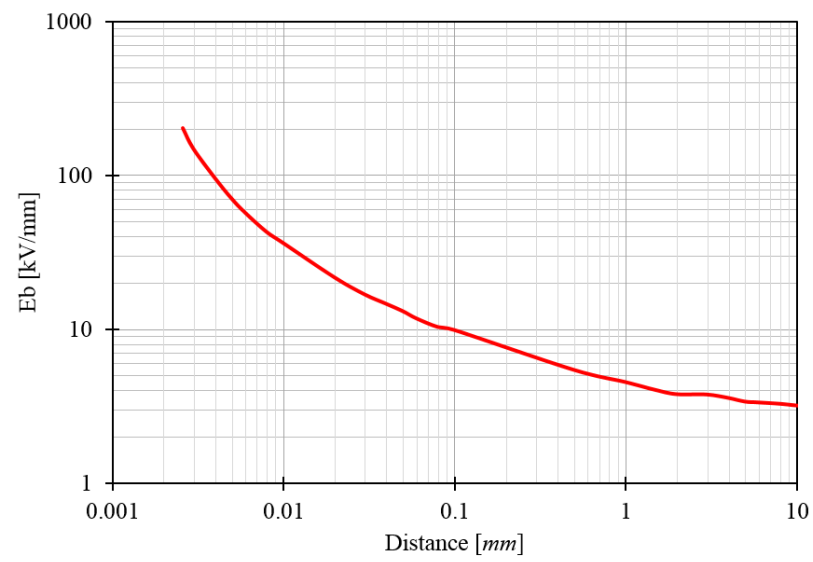

Fig. 3. Paschen's curve for air at standard ambient pressure.

The examined combinations of conductor diameter and enamel thickness (i.e. grade) are listed in TABLE I. In the FE electrostatic simulations, the enamel thickness has been chosen as the minimum value guaranteed by the magnet wire manufacturer for each grade (GR). The choice of selecting the thinner enamel layer allows to account for a reasonable safety margin. For all the analysed combinations, a polyamide-imide enamel insulation has been considered (relative permeability $\left.\varepsilon_{\mathrm{r}}=4\right)$.

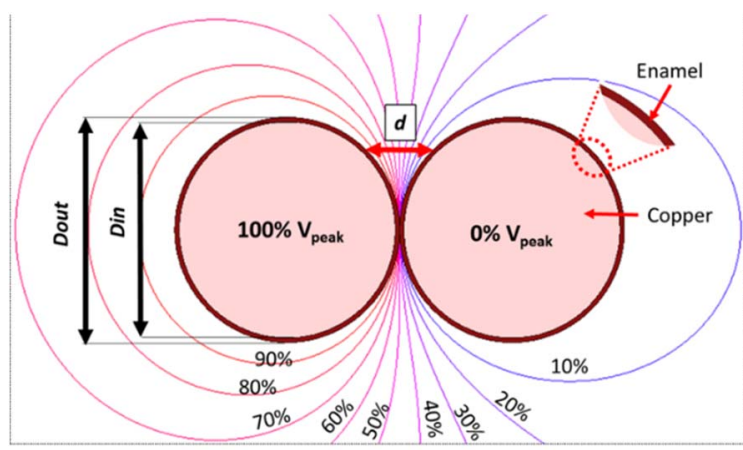

Fig. 4. FE model for the turn-to-turn insulation analysis.

TABLE I ANALYSED WIRE DIAMETERS AND GRADES

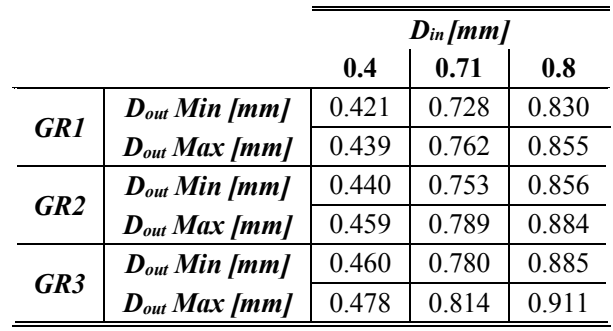

Fig. 5 provides an FE simulation outcome, where a $0.4 \mathrm{~mm}$ magnet wire with GR1 insulation is simulated when a turn-to-turn voltage of $640 V_{\text {peak }}$ is applied. In Fig. 6, the corresponding electric field distribution along the enamel surface is shown. It can be observed that with this combination of wire diameter, GR and turn-to-turn voltage, there is a risk of PD inception for gap distances ranging from $6 \mu \mathrm{m}$ to $40 \mu \mathrm{m}$. For sake of completeness, an example of PD-free configuration is also highlighted in Fig. 6, where the magnet wire layout (i.e. diameter and GR) is kept the same and a $340 V_{\text {peak }}$ voltage is applied. In this case, the curve representing the resulting electric field distribution on the enamel surface is located below the Paschen's curve. Hence, the risk of PD inception is avoided.

For all the studied configurations, the maximum 'safe' voltage applicable between two adjacent turns (i.e. voltage limit below which PD-free operations are guaranteed) is determined and the obtained results are summarised in TABLE II. As expected, the PD-free voltage limit rises as the magnet wire grade (i.e. enamel thickness) increases. Further, an increment of PDIV is noted with the adoption of larger wire diameters

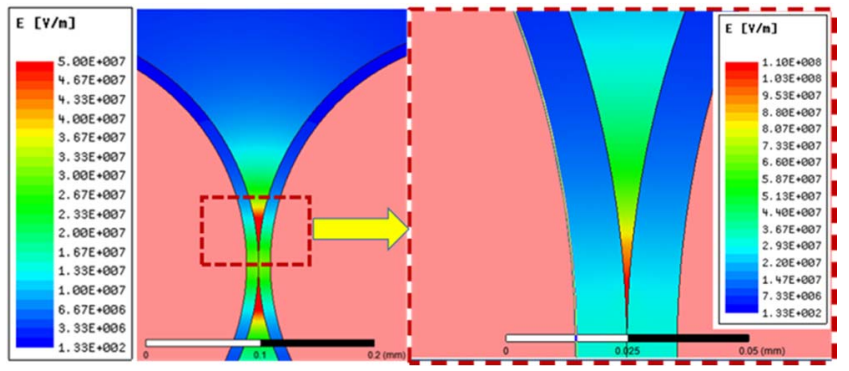

Fig. 5. FE simulation results for $0.4 \mathrm{~mm}, \mathrm{GR} 1$ wire and $V_{\text {peak }}=640 \mathrm{~V}$ 


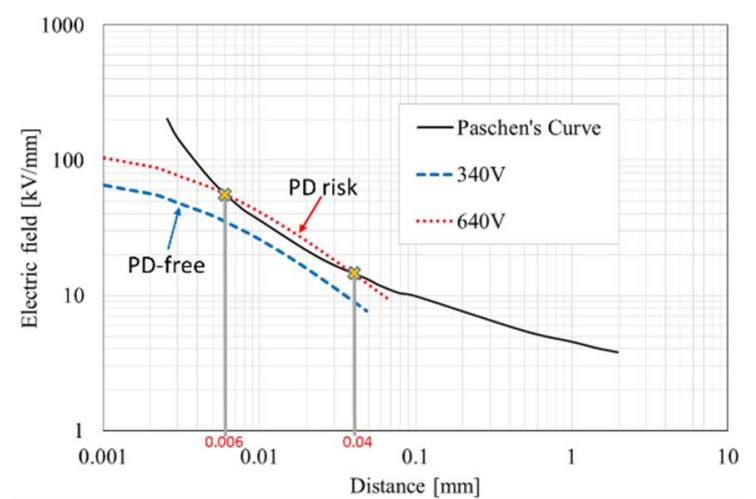

Fig. 6 Electric field distribution for $0.4 \mathrm{~mm}$ and GR1 wire.

TABLE II TURN-TO-TURN PDIV FOR EACH STUDIED CONFIGURATION

\begin{tabular}{l|c|c|c} 
& \multicolumn{3}{c}{$D_{\text {in }}$ [mm] } \\
\multicolumn{1}{c}{} & $\mathbf{0 . 4}$ & $\mathbf{0 . 7 1}$ & $\mathbf{0 . 8}$ \\
\hline GR1 & $540 \mathrm{~V}$ & $580 \mathrm{~V}$ & $580 \mathrm{~V}$ \\
\hline $\boldsymbol{G R 2}$ & $640 \mathrm{~V}$ & $720 \mathrm{~V}$ & $740 \mathrm{~V}$ \\
\hline $\boldsymbol{G R 3}$ & $740 \mathrm{~V}$ & $880 \mathrm{~V}$ & $880 \mathrm{~V}$ \\
\hline \hline
\end{tabular}

\section{EXPERIMENTAL VALIDATION}

The discussed FE model has been experimentally validated. As illustrated in Fig. 7, a set of 5 motorettes have been manufactured and wound adopting a GR2, $0.4 \mathrm{~mm}$ diameter magnet wire and a $0.13 \mathrm{~mm} \mathrm{Nomex}{ }^{\circledR}$ liner. For practical convenience, these prototypes (i.e. motorette) are scaled down compared to the actual PMSM's stator, while keeping the same shape. It is worthy to point out that the dimensions mismatch does not have influence on the PDIV, thus the experiments validity is preserved. Finally, the motorettes are not impregnated, in order to consider the worst-case scenario [31].

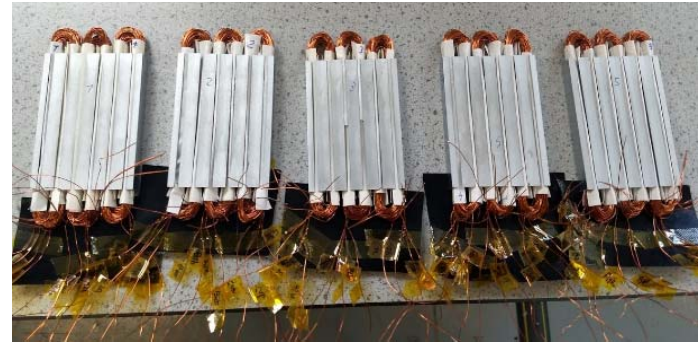

Fig. 7. Motorettes used during the validation campaign.

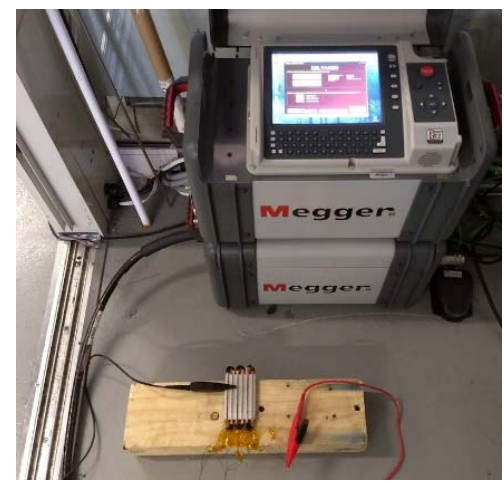

Fig. 8. Dissipation factor test.
For the turn-to-turn insulation subsystem, the PDIV has been measured by the dissipation factor (or $\tan \delta$ ) tip-up test (i.e. indirect method), using the equipment in Fig. 8. After the tests campaign, the data have been post-processed through the 2-parameters Weibull distribution. The measured dissipation factor (mean value of Weibull distribution) as function of the excitation voltage is reported in Fig. 9. From Fig. 9, it is possible to observe an increment of the $\tan \delta$ (i.e. inception of PD), for excitation voltages above $660 \mathrm{~V}$. This experimental value is very close to the one predicted by the FE simulations. Indeed, a turn-to-turn PDIV of $640 \mathrm{~V}$ (see TABLE II) is expected, when a GR2, $0.4 \mathrm{~mm}$ diameter magnet wire is simulated. These experimental results have been also confirmed through the PDIV direct measurement using a Techimp PD-Base ${ }^{\circledR}$ and a TEM Antenna as PD detector.

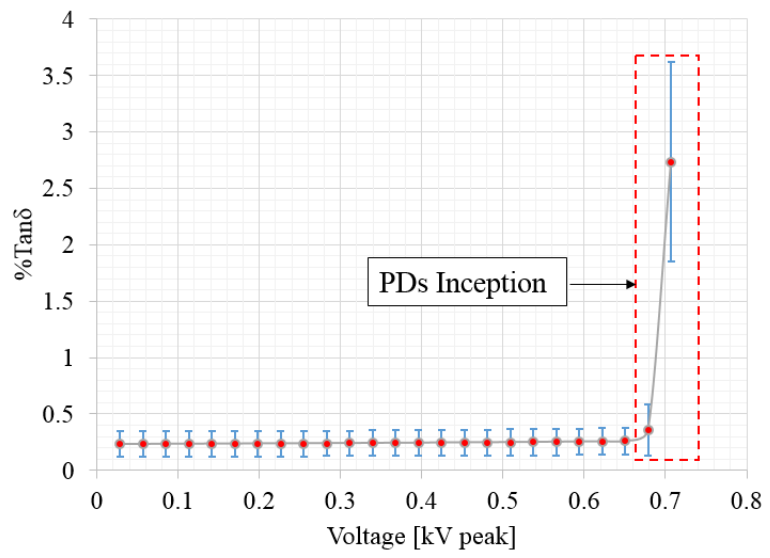

Fig. 9. \%Tan $\delta$ vs applied voltage for turn-to-turn insulation

\section{INFLUENCE OF INSULATION CHOICE ON THE PMSM PERFORMANCE}

In this section, the influence of the insulation choice on the PMSM torque density is investigated. The cross sectional view of the analysed EM is depicted in Fig. 10, whilst the main design parameters are listed in TABLE III. The quantities constraining the torque density are the wire fill factor $f f_{W}$ (i.e. slot fill factor considering the wire insulation) and the maximum (continuous) current density $J_{M a x}$. In the following, these parameters will be kept constant and equal to $50 \%$ for the fill factor and $6.3 \mathrm{~A} / \mathrm{mm}^{2}$ for the current density. The slot copper fill factor $f f_{C}$ (i.e. ratio between copper and net slot surface area) will depend on the adopted magnet wire grade and liner thickness.

Being the PMSM distributed wound, an additional galvanic separation between different phases is required in both active (i.e. slot) and end-winding sections of the coils. For this reason, a horizontal slot divider (placed between coils) is included within the slot. Due to the modest thickness of the chosen slot divider (i.e. $0.13,0.18$ and $0.25 \mathrm{~mm}$ ), the slot area is marginally affected by its presence (i.e. $0.41 \%$, $0.57 \%$ and $0.79 \%$ of the slot area respectively). Thus, it has been decided to use a $0.18 \mathrm{~mm}$ slot divider and liner thickness, for all the performed analysis. All the possible combinations of insulation GR have been simulated, for every considered wire diameter (i.e. $0.4,0.71$ and $0.8 \mathrm{~mm}$ ). For brevity reason, 
only the most and the less conservative designs, in terms of insulation grade, are listed in TABLE IV.

Since the winding layout is fixed (i.e. distributed winding), as well as the $f f_{W}$, the combination of wire diameter and GR determines the maximum number of parallel strands per conductor. However, the number of parallel strands influences the phase current and therefore the PMSM continuous torque, because the maximum current density is constrained by the available cooling method [32, 33].

In TABLE V, the PMSM performance, concerning copper fill factor, phase current and developed torque (at base speed), are summarized for the insulation configurations reported in TABLE IV. The torque is calculated by $\mathrm{FE}$ transient electromagnetic analysis using the commercial software Ansys ${ }^{\circledR}$ Maxwell 2D.

From TABLE V's findings, it is clear the impact that both wire diameter and insulation GR have on the developed torque. In fact, increasing the insulation thickness, while keeping constant the $f f_{W}$, leads to smaller slot area occupied by copper and then lower electromagnetic torque for the same current density. If details regarding the available PEC and cable length are available, then, it is possible to use (1)-(5) for evaluating which of the analysed configurations are PD-free. For example, assuming the parameters listed in TABLE VI, the maximum voltage limit for which PD-free operations are guaranteed is equal to $610 \mathrm{~V}$. Therefore, only three configurations can guarantee PD-free operations, namely ' $\mathrm{B}$ ', ' $D$ ' and ' $F$ '. Nonetheless, this enhanced reliability feature negatively impacts the torque density performance, as earlier verified.

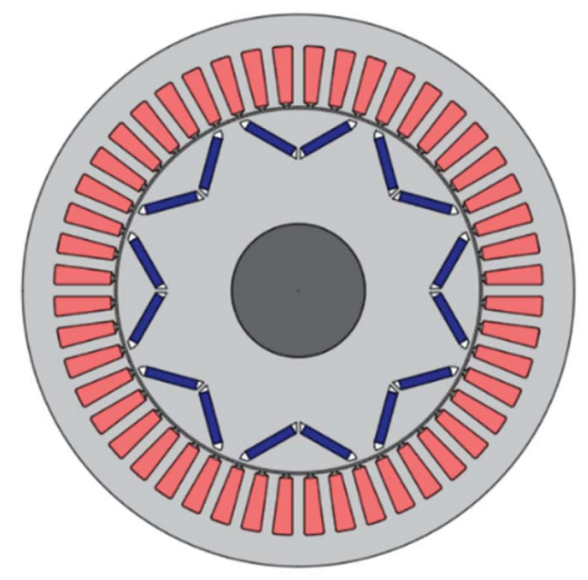

Fig. 10. Cross section of the PMSM under study

TABLE III Main Parameters of the CASE-STUdy PMSM

\begin{tabular}{ccc}
\hline \hline Design parameter & Quantity & Unit \\
\hline Outer diameter, Dout & 290 & $\mathrm{~mm}$ \\
\hline Axial length, L & 200 & $\mathrm{~mm}$ \\
\hline Base speed, $\mathrm{n}$ & 2100 & $\mathrm{rpm}$ \\
\hline Slot number, Q & 48 & - \\
\hline Pole pairs, $\mathrm{p}$ & 4 & - \\
\hline Windings layout & Distr. & - \\
\hline PM grade & $\mathrm{N} 42 \mathrm{UH}$ & - \\
\hline Phases & 3 & - \\
\hline Max fill factor (wire), $\mathrm{ff}_{\mathrm{W}}$ & 50 & $\%$ \\
\hline Current density, $\mathrm{J}_{\mathrm{Max}}$ & 6.3 & $\mathrm{~A} / \mathrm{mm}^{2}$ \\
\hline \hline
\end{tabular}

TABLE IV LIST OF ANALYSED INSULATION CONFIGURATIONS

\begin{tabular}{lcc}
\hline \hline $\begin{array}{l}\text { PMSM } \\
\text { conf. }\end{array}$ & $\begin{array}{c}\text { Wire (core) } \\
\text { diam. [mm] }\end{array}$ & Grade \\
\hline $\mathrm{A}$ & 0.8 & 1 \\
\hline $\mathrm{B}$ & 0.8 & 3 \\
\hline $\mathrm{C}$ & 0.71 & 1 \\
\hline $\mathrm{D}$ & 0.71 & 3 \\
\hline $\mathrm{E}$ & 0.4 & 1 \\
\hline $\mathrm{F}$ & 0.4 & 3 \\
\hline \hline
\end{tabular}

TABLE V PMSM PERFORMANCE FROM FE SiMULATIONS

\begin{tabular}{lccc}
\hline $\begin{array}{l}\text { PMSM } \\
\text { conf. }\end{array}$ & $\begin{array}{c}\mathrm{ff}_{\mathrm{C}} \\
{[\%]}\end{array}$ & $\begin{array}{c}\text { Phase current } \\
{[\text { Arms] }}\end{array}$ & $\begin{array}{c}\text { Average torque } \\
{[\mathrm{Nm}]}\end{array}$ \\
\hline $\mathrm{A}$ & 44.2 & 240.7 & 393.5 \\
\hline $\mathrm{B}$ & 34.9 & 190 & 310.7 \\
\hline $\mathrm{C}$ & 42.2 & 229.5 & 375.8 \\
\hline $\mathrm{D}$ & 35.8 & 189.6 & 310 \\
\hline $\mathrm{E}$ & 40.7 & 221.7 & 363.2 \\
\hline $\mathrm{F}$ & 33.8 & 183.7 & 300 \\
\hline \hline
\end{tabular}

TABLE VI Drive PARAMETERS USED FOR PDIV CALCULATION

\begin{tabular}{ccc}
\hline \hline Parameter & Quantity & Unit \\
\hline Rise time & 50 & $\mathrm{~ns}$ \\
\hline Cable length & 1 & $\mathrm{~m}$ \\
\hline Enhancement factor & 1.63 & - \\
\hline DC link voltage & 540 & $\mathrm{~V}$ \\
\hline \hline
\end{tabular}

\section{CONCLUSIONS}

As electric drives keep being pushed to their limits in terms of performance, it is becoming evident that reliability and lifetime aspects need to be considered at an early stage in the design process. This paper is oriented towards such methodology, as it clearly shows and highlights how the choice of the insulation system is not only important for EMs lifetime, but it also has a significant effect on their performances.

In this work, the problem of voltage enhancement due to fast switching devices has been investigated through transmission line theory and circuital simulations. It was confirmed that long cable distances (between converter and machine) and short rise times $\mathrm{SiC}$ MOSFETS ( $<50 \mathrm{~ns})$ can amplify the machine terminals voltage up-to $\approx 2$ times the DC link voltage. This might seriously compromise the reliability of low voltage, organic-insulated electrical machines.

Combining FE electrostatic simulations and Paschen's law, the partial discharges inception voltage for the turn-to-turn insulation in a low voltage machine has been determined. The proposed model has been experimentally validated via PD measurement and a good fit was revealed. Nonetheless, further tests are planned using PWM-like excitation voltage.

A pre-designed traction PMSM has been used for investigating the impact of insulation choice on the torque-production capability. In particular, it was shown that the considered PMSM demands a higher grade insulation in order to guarantee reliable operations without any risk of PD inception. However, the PD-free operations come at the cost of a non-negligible torque reduction; therefore a trade-off between performance and lifetime of the machine is required to identify the optimum design. 


\section{REFERENCES}

[1] A. Cavallini, "Reliability of low voltage inverter-fed motors: What have we learned, perspectives, open points," in 2017 International Symposium on Electrical Insulating Materials (ISEIM), 2017, pp. 1322.

[2] D. Fabiani, "Accelerated degradation of ac-motor winding insulation due to voltage waveforms generated by adjustable speed drives," $\mathrm{PhD}$, University of Bologna, Bologna, Italy, 2003.

[3] R. Kerkman, D. Leggate, and G. Skibinski, "Interaction of drive modulation and cable parameters on AC motor transients," in IAS '96. Conference Record of the 1996 IEEE Industry Applications Conference Thirty-First IAS Annual Meeting, 1996, pp. 143-152 vol.1.

[4] B. Taghia, B. Cougo, H. Piquet, D. Malec, A. Belinger, and J.-P. Carayon, "Overvoltage at motor terminals in SiC-based PWM drives," Mathematics and Computers in Simulation, 2018/09/27/ 2018.

[5] A. M. E.-. Refaie, J. P. Alexander, S. Galioto, P. B. Reddy, K. K. Huh, P. d. Bock, et al., "Advanced High-Power-Density Interior Permanent Magnet Motor for Traction Applications," IEEE Transactions on Industry Applications, vol. 50, pp. 3235-3248, 2014.

[6] "IEC 60034-18-42:2017 Rotating Electrical Machines - Part 18-42: Partial discharge resistant electrical insulation systems (Type II) used in rotating electrical machines fed from voltage converters Qualification tests," ed: IEC, 2017.

[7] G. C. Stone, I. Culbert, E. A. Boulter, and H. Dhirani, Electrical Insulation for Rotating Machines: Design, Evaluation, Aging, Testing, and Repair: Wiley, 2014.

[8] V. Madonna, P. Giangrande, and M. Galea, "Electrical Power Generation in Aircraft: Review, Challenges, and Opportunities," IEEE Transactions on Transportation Electrification, vol. 4, pp. 646-659, 2018.

[9] W. Cao, B. C. Mecrow, G. J. Atkinson, J. W. Bennett, and D. J. Atkinson, "Overview of Electric Motor Technologies Used for More Electric Aircraft (MEA)," IEEE Transactions on Industrial Electronics, vol. 59, pp. 3523-3531, 2012.

[10] P. Giangrande, V. Madonna, G. Sala, A. Kladas, C. Gerada, and M. Galea, "Design and Testing of PMSM for Aerospace EMA Applications," in IECON 2018 - 44th Annual Conference of the IEEE Industrial Electronics Society, 2018, pp. 2038-2043.

[11] M. Ehsani, Y. Gao, and J. M. Miller, "Hybrid Electric Vehicles: Architecture and Motor Drives," Proceedings of the IEEE, vol. 95, pp. 719-728, 2007.

[12] C. Sciascera, P. Giangrande, C. Brunson, M. Galea, and C. Gerada, "Optimal design of an electro-mechanical actuator for aerospace application," in IECON 2015 - 41st Annual Conference of the IEEE Industrial Electronics Society, 2015, pp. 001903-001908.

[13] P. Giangrande, V. Madonna, S. Nuzzo, and M. Galea, "Design of Fault-Tolerant Dual Three-Phase Winding PMSM for Helicopter Landing Gear EMA," in 2018 IEEE International Conference on Electrical Systems for Aircraft, Railway, Ship Propulsion and Road Vehicles \& International Transportation Electrification Conference (ESARS-ITEC), 2018, pp. 1-6.

[14] V. Madonna, P. Giangrande, C. Gerada, and M. Galea, "Thermal analysis of fault-tolerant electrical machines for aerospace actuators," IET Electric Power Applications, 2018.

[15] J. W. Bennett, B. C. Mecrow, D. J. Atkinson, and G. J. Atkinson, "Safety-critical design of electromechanical actuation systems in commercial aircraft," IET Electric Power Applications, vol. 5, pp. 37 47, 2011.

[16] V. Madonna, P. Giangrande, C. Gerada, and M. Galea, "Thermal analysis of fault-tolerant electrical machines for more electric aircraft applications," The Journal of Engineering, vol. 2018, pp. 461-467, 2018.

[17] V. Madonna, P. Giangrande, L. Lusuardi, A. Cavallini, and M. Galea, "Impact of thermal overload on the insulation aging in short duty cycle motors for aerospace," in 2018 IEEE International Conference on
Electrical Systems for Aircraft, Railway, Ship Propulsion and Road Vehicles \& International Transportation Electrification Conference (ESARS-ITEC), 2018, pp. 1-6.

[18] A. Al-Timimy, P. Giangrande, M. Degano, Z. Xu, M. Galea, C. Gerada, et al., "Design and Losses Analysis of a High Power Density Machine for Flooded Pump Applications," IEEE Transactions on Industry Applications, vol. 54, pp. 3260-3270, 2018.

[19] A. Cavallini, D. Fabiani, and G. C. Montanari, "Power electronics and electrical insulation systems - Part 1: Phenomenology overview," IEEE Electrical Insulation Magazine, vol. 26, pp. 7-15, 2010.

[20] Z. Huang, T. Yang, P. Giangrande, S. Chowdhury, M. Galea, and P. Wheeler, "An Active Modulation Scheme to Boost Voltage Utilization of the Dual Converter With a Floating Bridge," IEEE Transactions on Industrial Electronics, vol. 66, pp. 5623-5633, 2019.

[21] E. Persson, "Transient effects in application of PWM inverters to induction motors," IEEE Transactions on Industry Applications, vol. 28, pp. 1095-1101, 1992.

[22] M. F. Rahman, T. Haider, E. Haque, T. R. Blackburn, and C. Grantham, "Modelling and experimental studies of effects of steep fronted inverter waveforms on motor and supply cabling and their remedies," in Proceedings of the IEEE 1999 International Conference on Power Electronics and Drive Systems. PEDS'99 (Cat. No.99TH8475), 1999, pp. 519-524 vol.1.

[23] L. V. Bewley, "Traveling Waves on Transmission Systems," Transactions of the American Institute of Electrical Engineers, vol. 50, pp. 532-550, 1931.

[24] S. A. Odhano, P. Giangrande, R. Bojoi, and C. Gerada, "Selfcommissioning of interior permanent magnet synchronous motor drives with high-frequency current injection," in 2013 IEEE Energy Conversion Congress and Exposition, 2013, pp. 3852-3859.

[25] CREE. (12/2018). CAS120M12BM2, 1.2kV All-Silicon Carbide HalfBridge Module. Available: https://www.wolfspeed.com/cas $120 \mathrm{~m} 12 \mathrm{bm} 2$.

[26] CREE. E3M0065090D Datasheet, Available: https://www.wolfspeed.com/downloads/dl/file/id/1305/product/358/e 3m0065090d.pdf.

[27] P. Mancinelli, S. Stagnitta, and A. Cavallini, "Qualification of Hairpin Motors Insulation for Automotive Applications," IEEE Transactions on Industry Applications, vol. 53, pp. 3110-3118, 2017.

[28] T. W. Dakin, G. Luxa, G. Oppermann, J. Vigreux, G. Wind, and H. Winkelnkemper, "Breakdown of gases in uniform fields. Paschen curves for nitrogen, air and hexafluoride," Electra, vol. 32, pp. 61-82, 1974.

[29] A. Al-Timimy, M. Al-Ani, M. Degano, P. Giangrande, C. Gerada, and M. Galea, "Influence of rotor endcaps on the electromagnetic performance of high-speed PM machine," IET Electric Power Applications, vol. 12, pp. 1142-1149, 2018.

[30] H. Okubo, N. Hayakawa, and G. C. Montanari, "Technical Development on Partial Discharge Measurement and Electrical Insulation Techniques for Low Voltage Motors Driven by Voltage Inverters," IEEE Transactions on Dielectrics and Electrical Insulation, vol. 14, pp. 1516-1530, 2007.

[31] A. Al-Timimy, G. Vakil, M. Degano, P. Giangrande, C. Gerada, and M. Galea, "Considerations on the Effects That Core Material Machining Has on an Electrical Machine's Performance," IEEE Transactions on Energy Conversion, vol. 33, pp. 1154-1163, 2018.

[32] V. Madonna, P. Giangrande, A. Walker, and M. Galea, "On the Effects of Advanced End-Winding Cooling on the Design and Performance of Electrical Machines," in 2018 XIII International Conference on Electrical Machines (ICEM), 2018, pp. 311-317.

[33] V. Madonna, A. Walker, P. Giangrande, G. Serra, C. Gerada, and M. Galea, "Improved Thermal Management and Analysis for Stator EndWindings of Electrical Machines," IEEE Transactions on Industrial Electronics, vol. 66, pp. 5057-5069, 2019. 